\title{
WAYS TO DETERMINE THE TECHNICAL STATUS OF THE VEHICLES' BRAKING SYSTEM BY MEANS OF GENERAL DIAGNOSIS
}

\author{
Paul TODEA \\ todeapaul@yahoo.ro \\ Daniel LAZĂR \\ lazardaniel73@yahoo.com \\ MINISTRY OF NATIONAL DEFENCE, BUCHAREST,ROMANIA
}

\begin{abstract}
Vehicles' breaking system is one of the basic elements that lead to the maintenance of technical and road safety during transport activities on public roads or other special conditions. Therefore, particular attention is paid to all maintenance work planned or occasionally carried out on such system, as a high coefficient of vehicles availability results in an increased percentage of their productivity. Of course, there is diagnosis equipment for each element, and the brake booths within MOT centres accurately indicate the values of the measured parameters, following repair, adjustment and control operations for troubleshooting. Still, there are certain cases requesting the check of breaking system either analytically or by field experiments, i.e. when vehicles are driven on rough and rugged ground, during military specific missions and activities, where their performance no longer allows specialized equipment or when such equipment does not exist. This works presents alternatives to determine the technical condition of the braking system by means of typical solutions for the general diagnosis type.
\end{abstract}

\section{KEYWORDS:}

Breaking system, general diagnosis, breaking space, analytical method, field experiments

\section{Requirements for Braking Systems}

A driven car has a kinetic energy, the value of which is determined by its weight and speed; for constant movement there is a balance between the driving force and the resisting forces (running, downhill, acceleration) that contravenes to the vehicle movement. Therefore, to reduce the speed or to stop the vehicle, an additional counter- force that ensures immobilization is necessary. Such counter-force is provided by the brake.

Any vehicle shall be provided with two braking systems: service brake and assist brake (parking brake). Both systems must be perfectly tuned and operate efficiently and quickly, independently of each other. 
The braking qualities of a vehicle are a determining factor in traffic safety and influences to a remarkable extent the average driving speed.

The braking system should meet the following requirements (Lespezeanu, 2000):

- achieve equal braking forces at the wheels of the same axle;

- achieve progressive braking, proportional to the pedal force;

- brake effort should be distributed on wheels proportionally to their load;

- avoid wheel slipping at energy efficient brakes.

2. Ways to Determine the Technical Condition of the Braking System

The general diagnosis is to determine the technical condition of the braking system by means of diagnostic parameters such as braking space, deceleration and pedal load, measured in a braking process performed in the fastest possible stroke and starting from a certain initial speed.

Checking the braking system by determining the minimal braking space

The minimum braking space is one of the basic parameters to determine the braking system's technical condition. In the same time, it is important for the start moment of the brake to be the same for all wheels, and for the brake load to be uniform.

The basic condition required for the braking system from the point of view of the braking space is to get certain values for the given conditions of movement, conditions featured by the adherence coefficient and the vehicle speed $v$.

The minimal braking space is set either analytically, or through field experiments (Stratulat and Manea, 1982):

a) Analytical method

The total space of vehicle breaking to stop $S_{0}$ is calculated as follows:

$$
S_{0}=\left(t_{1}+t_{2}\right) \frac{v}{3,6}+S_{f}
$$

where:

$$
t_{1}-\text { driver's reaction time }=0.4-1.0 \mathrm{~s} ;
$$

$t_{2}$ - time to transfer the load to brakes $=0.2-0.4 \mathrm{~s}$, for hydraulic brakes; 0.6-1.0 $\mathrm{s}$, for pneumatic brakes;

$v$ - vehicle speed (in $\mathrm{km} / \mathrm{h}$ );

$S_{f}$ - braking space (in $m$ )

Theoretically, the braking space is calculated as follows:

$$
S_{f}=\frac{v}{26 g \varphi}
$$

where: $\begin{aligned} g= & \text { gravitational acceleration (in } \\ & \mathrm{m} / \mathrm{s}^{2} \text { ); }\end{aligned}$

$\varphi=$ adhesion coefficient.

Actually, the braking space also depends on other factors except the speed and the adhesion coefficient. Among these, the following are mentioned:

- vehicle adhesion weight $G_{a}$;

- technical condition of system's elements (distance between friction seals and braking drums, pressure modification in the drive system etc.).

The calculation of the braking space, considering such factors, is the following:

$$
S_{f}=\frac{G_{a} v}{26 g\left[F_{f} \lambda+G_{a} \varphi(1-\lambda)\right]}(m)
$$

where:

$F_{f}=\frac{M_{f}}{r_{r}}$ wheel braking force, in $k g f ;$

$M_{r}$ - wheel brake torque, in $\mathrm{kgf}$;

$r_{r}$ - wheel rolling radius;

$\lambda-$ loss coefficient by slipping representing the ration between wheel peripheral speed and vehicle speed. The values are between $0.88-0.98$.

Given the above-mentioned, it follows that in order to calculate the analytical braking space, it is necessary to know the weight of the vehicle at the time of braking, the speed in the moment of braking, the adhesion coefficient $\varphi$ and the wheel braking torque or force.

The definition of the wheel braking torque or force needs special tools that are not always owed by operating staff. For this 
reason, most frequently, during operation activities, the minimal braking space is defined by means of experiments.

\section{b) through field experiments}

This widely practiced method offers the possibility to standardize the adjustment of wheel brakes besides measuring the braking space. Such method is laborious, requiring long enough time to prepare and execute it.

During preparatory operations, it is mandatory to check the speedometer to precisely determine the initial speed. Besides this, the method also proves its aplicability only on a certain route and under certain conditions of temperature and humidity, which makes it unusable for most of the days of the year.

The definition of the braking space is performed by mean of fully loaded vehicle, on a straight and horizontal road with smooth, hard and dry surface (asphalt or concrete), at air temperature of $-10^{\circ} \mathrm{C}$ up to $+25^{\circ} \mathrm{C}$, so that the adhesion coefficient is not lower than 0.7 . If necessary, the experiment can also be performed on hard, well-knocked, dust-free ground. The tests can also be performed if the vehicle is empty.

Before performing the experiments, the braking drums and shoes shall be cooled by a stroke, without using the brakes or by at least 25 minutes parking.

The vehicle is set on the road section selected under the above conditions and accelerated to the exact measured speed of 30,40 or $50 \mathrm{~km} / \mathrm{h}$, after setting a constant drive (the speed is constantly maintained). The vehicle suddenly breaks off by means of service brake.

Braking shall be performed by pressing the brake pedal fast, but shockfree. In case of hydraulic systems, the pedal is pressed with a force equal to the maximum that the driver can achieve $(60 \mathrm{~kg} f)$, while in case of pneumatic systems, the pedal is pressed until taut.
Braking shall be performed twice for each initial test speed after a 10 minutes braking time.

In order to eliminate possible wind speed influences, the vehicle will reverse to the second braking.

The beginning of the brake is established by means of a device that projects paint on the road surface when the brake pedal is pressed. Given the traces left by the wheels on the road, the simultaneity of their action and the uniformity of the brake force distribution are established.

The length of the traces left by the wheels on the road represents the braking space, the dimension of which must fall within the limits prescribed in table no. 1, where values for vehicle type whose weight is greater than 9 tons are given for exemplification.

Table no. 1

\begin{tabular}{|c|c|c|c|}
\hline $\begin{array}{l}\text { Vehicle } \\
\text { type }\end{array}$ & Load & $\begin{array}{l}\text { Braking } \\
\text { space at } \\
\text { speed of } \\
30 \mathrm{~km} / \mathrm{h}\end{array}$ & $\begin{array}{c}\text { Max. } \\
\text { deceleration } \\
\mathrm{m} / \mathrm{s}^{2}\end{array}$ \\
\hline \multirow{2}{*}{$\begin{array}{l}\text { Truck } \\
\text { with } \\
\text { total } \\
\text { weight } \\
\text { higher } \\
\text { than } 9 \mathrm{t}\end{array}$} & $\begin{array}{c}\text { No } \\
\text { load }\end{array}$ & 11.0 & 4.2 \\
\hline & $\begin{array}{l}\text { Total } \\
\text { load }\end{array}$ & 13.5 & 3.5 \\
\hline
\end{tabular}

The parking brake is tested by means of fully loaded vehicle sitting on a ramp with a hard, dry, smooth surface, whose groundswell is $16 \%$.

The hand brake is pulled, the steering lever being held in this position by means of its lock. The vehicle shall remain in idle position for 15-20 minutes. When performing the test at maximum slope, the brake must immobilize the vehicle for at least 5 minutes.

The second experiment is performed in the same way, placing the vehicle on the slope, i.e. turning it to $180^{\circ}$. In such case, the vehicle shall remain idle for the same period of time. 
The check of the braking system by determining the maximum deceleration

A decelerometer (Figure no. 1) is used to measure the deceleration, prepared and installed on the board of the car.

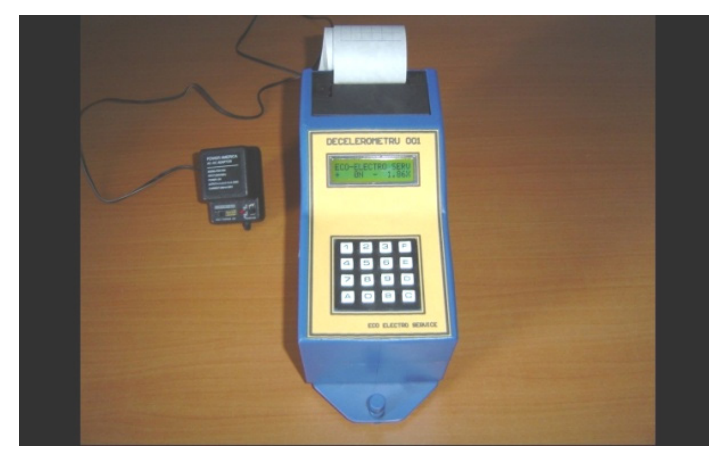

Figure no. 1 Decelerometru D 001 Source: http://www.ecoelectroservice.ro/p10.html

The test shall be carried out on a road section that meets the same conditions as when determining the braking area.

At a steady speed of travel of $30 \mathrm{~km} / \mathrm{h}$, press quickly and firmly on the service brake pedal. Read the maximum deceleration obtained and compare with the values prescribed in the technical instructions. As the maximum deceleration depends only on the braking force, it is not necessary to precisely determine the initial speed, so that this verification is much more simple.

\section{Conclusions}

The ways to check the braking efficiency provide different degrees of accuracy, depending on the accuracy with which the parameters involved in performing the checks are determined. In addition to this, the results of these checks depend to a large extend on the way the driver is used or not to a vehicle driven during these teste and also on the way the driver presses the brake pedal.

The methods for checking the braking efficiency have different degrees of accuracy, depending on the accuracy with which the parameters involved in the checks are determined. In addition to this, the results of the checks depend to a large extent on the way the driver is used or the vehicle he is driving during the check and how he works on the brake pedal.

The braking distance measurement method provides good results, but the degree of accuracy of this check depends largely on the accuracy of the vehicle's speed setting at the time of braking.

The second method, to determine the maximum deceleration, produces good results, quite accurately recording the braking behavior of the car, the current equipment being performing, its construction eliminating the errors characteristic of decelerographs and mechanical decelerometers.

\section{REFERENCES}

Lespezeanu, I. (2000). Mentenanţa automobilelor, Bucureşti: Editura Academiei Tehnice Militare.

Stratulat, M. \& Manea, C. (1982). Fiabilitatea şi diagnosticarea automobilelor, Bucureşti: Editura Militară.

www.ecoelectroservice.ro/p10.html. 